\title{
Innovation and Exploration of Teaching Management Based on Credit System
}

\author{
Yu Zhao \\ Jincheng College \\ Nanjing University of Aeronautics and Astronautics \\ Nanjing, Jiangsu, China 211156
}

\begin{abstract}
Implementation of credit system is a significant approach to deepen the reform of talents cultivation pattern of higher education, stimulate students' subjectivity and facilitate all-round development of students. Colleges and universities are supposed to hold the concept of talents cultivation and teaching, fully utilize the credit system to innovate teaching management in the perspectives of credit obtaining, credit management and study evaluation. Provide broader alternatives, more rights and prospects for students to lean knowledge, cultivate their capabilities and develop their quality, which furnishes a system safeguard for students' development. Combining the cases of innovation and exploration of teaching management, this paper is intended to give some suggestion for the reformation of credit system of higher education on the basis of core concept of credit system.
\end{abstract}

Keywords-credit system; teaching management; independent choice; all-round development

\section{INTRODUCTION}

In order to meet the requirements of new generation's innovative capability and individual quality in the circumstances of new normal economy, to fully exploit the extant education resources as well, a lot of colleges and universities begin to reform their interior teaching management system. The most significant measure is to regard credit system as the breakthrough of teaching management reformation. To implement credit system is one of the important approaches to deepen the reform of talents cultivation pattern of higher education, stimulate students' subjectivity and facilitate all-round development of students. This paper sticks to the teaching management philosophy, i.e., "student-oriented and promoting students' all-round development", relying on the exploration and innovation of teaching management, fully survey recent years' credit system reforming practice of higher education, expecting to provide a powerful system guarantee for students' development.

\section{CORE CONCEPT AND STRUCTURE OF CREDIT SySTEM MANAGEMENT}

In accordance with the talents cultivation objective of higher education, this paper clarifies the core concept of credit system from six perspectives: sense of responsibility, systematic knowledge, initiative spirit, practical ability, global outlook and comprehensive quality. The core concept is to regard promoting students' free and full development as the starting point and destination of all teaching activities; to provide excellent education resources and good studying conditions; to give students more opportunities, rights and room to make choice in perspectives of knowledge learning, competence cultivation and quality development; to guide students to develop consciously and independently. Therefore, with the guiding principles of "full demonstration, categorized recording, efficient communication, objective evaluation and using as needed", a main route diagram of credit management is established as "Fig. 1".
Full demonstration

Categorized recording

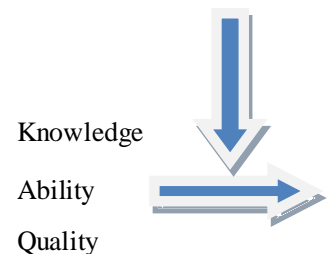

Quality

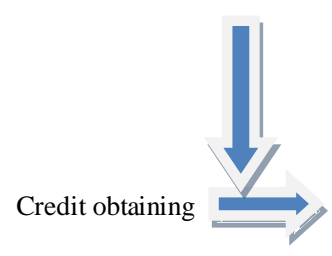

Effective exchange

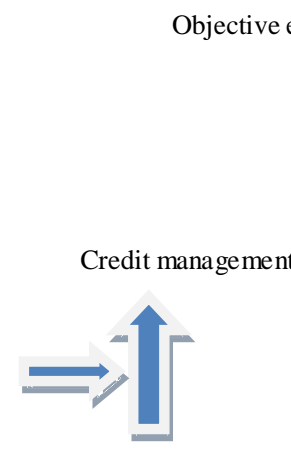

Credit substitution
Learning evaluation

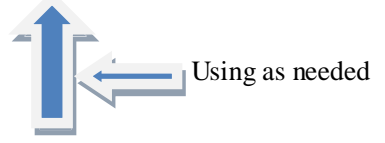

Credit use

Fig. 1. A main route diagram of credit management 
"Full demonstration" means that student can obtain corresponding credits in their knowledge, capability and quality; "categorized recording" refers to recording students' credits in a specified way such as specialty learning, quality development to directly reflect students' ability and quality structure; "efficient communication" means students can convert one type of credit to another by means of credit substitution, mainly referring to converting minor and activity credit to specialty learn credit; "objective evaluation" means to establish a new learning evaluation system, evaluate students' capability and level according to the differences of evaluation objectives and goals; "using as needed" implies after meeting the requirements of cultivation scheme and getting as more as possible credits, students have the opportunity to self-evaluate. By serial and progressive methods, the main route diagram of credit management is established, and in accordance with the diagram, this paper determines the credit system regulation as "Fig. 2", "redit obtaining" and "credit management" imply the concept of "full demonstration" and "categorized recording"; and the corresponding regulations of "credit substitution" "credit using" and "credit management" the ideas of "efficient communication" "using as needed" and "objective evaluation".

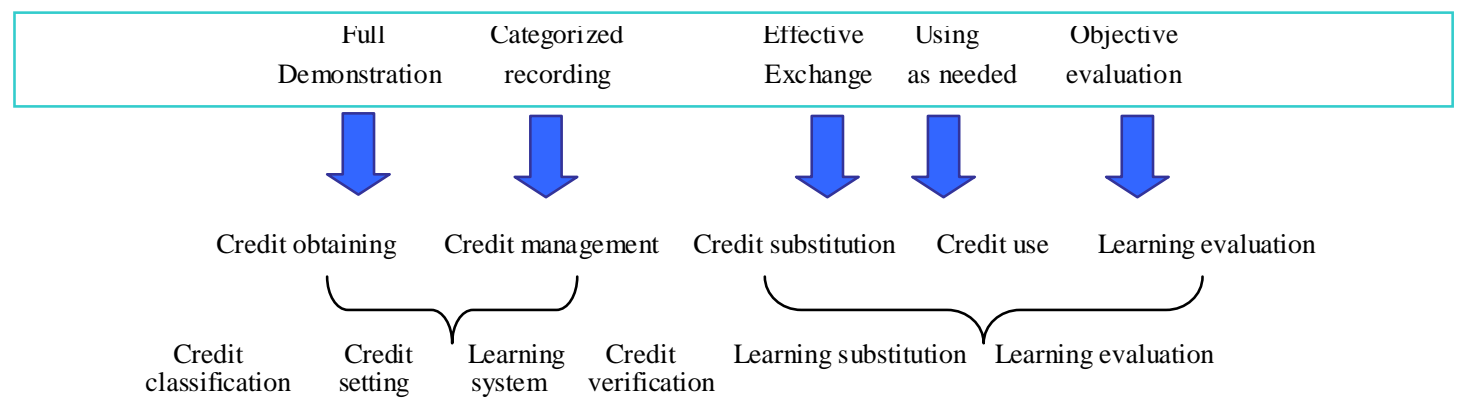

Fig. 2. Credit system regulation structure

\section{DESIGN OF CREDIT SYSTEM}

\section{A. Function and Classification of Credit}

Precisely knowing the meaning and function of credit is the foundation to implement credit system and teaching management. This paper believes that credit should reflect the comprehensiveness of knowledge, capability and quality and differences of quantity and quality. From the functional perspective, credit consists of scores and GPA, which record students' learning or activity process, evaluating students' efficiency of learning or activity; from the perspective of categorizing, credit can be divided into specialty credit and quality development credit, which are corresponding to learning and activity, demonstrated as course credit and activity credit. Credit is used to show the quantity of learning, GPA the quality of learning and credit-GPA (creditx GPAx weight coefficient) the performance of learning or activity.

\section{B. Obtaining and Management of Credit}

There are two main approaches to obtain credit, i.e. specialty learning and quality development. Establish a credit bank, open specialty learning account and quality development account to record students' specialty learning credit and quality development credit as "Fig. 3". Specialty learning includes major and minor oriented specialty learning credit, second major specialty learning credit, exchange learning credit and changing major specialty learning credit. Set up different sub-account in corresponding specialty learning account. In the process of learning major specialty, students have some alternatives to select their courses and arrange the schedule of learning on the basis of cultivation scheme and supervisor's instruction. Students can choose their minors in line with their individual characteristics. Guide students to learn purposely, designedly and actively.

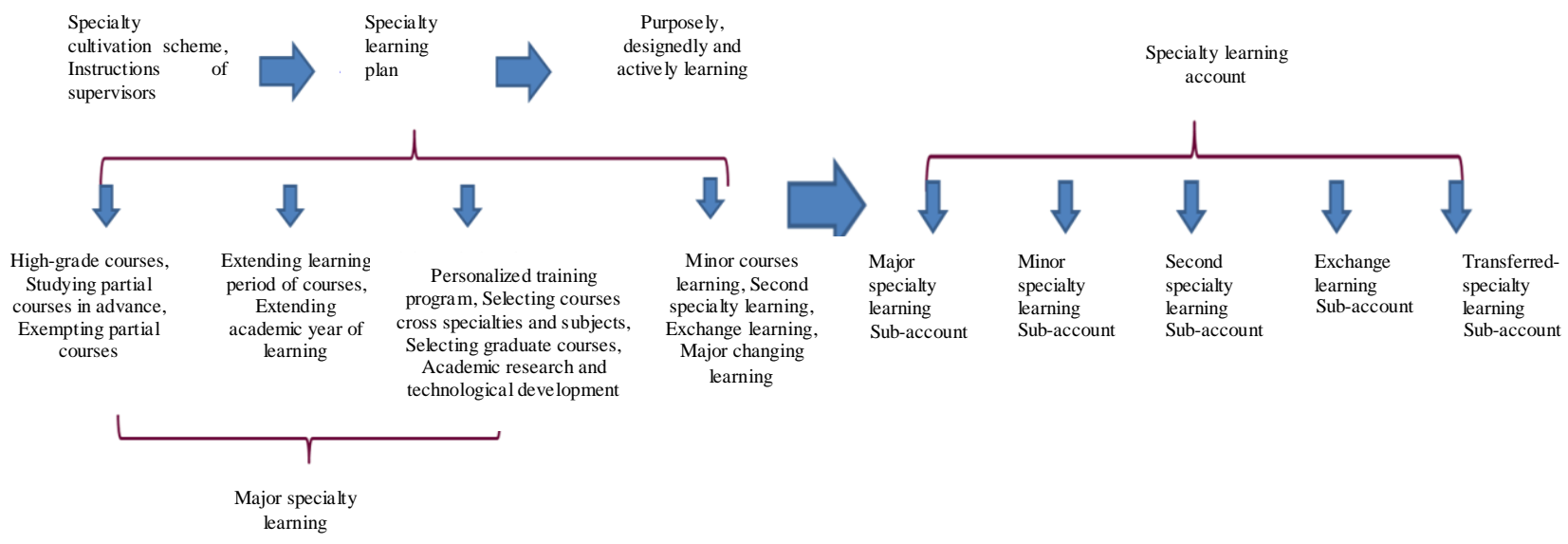

Fig. 3. Obtaining and recording of specialty learning credit 
Meanwhile, students can formulate and implement quality development plan to get credits according to their capability, interests, talents and employment demand. These credits can be recorded in the quality development credit as "Fig. 4", including scientific research, recreational and sports activities,
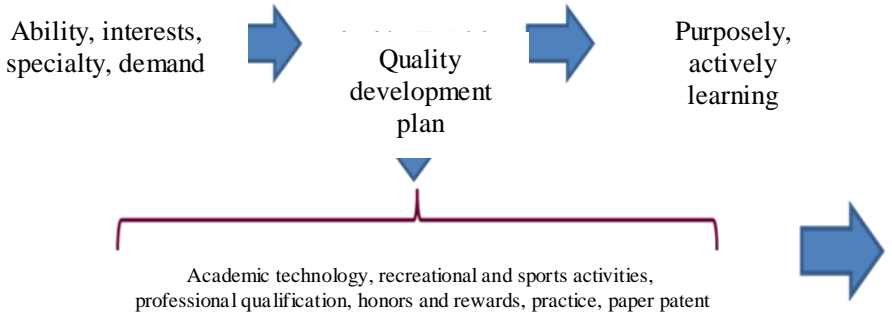

Fig. 4. Obtaining and recording of quality development credit

It needs to be clarified that all credits must be verified through a strict verification procedure. As long as the credits are compliance with the conditions and procedures and these credits gained in the university or participating in activities, it can be added to the corresponding sub-account; if the credit are not acquired in the university or participating in activities, it can be added to the corresponding account after application.

\section{The SUBSTITUTION, USE AND LEARNING EVALUATION OF CREDIT}

\section{A. Credit Substitution}

As mentioned earlier, the credits that students gains should record in the corresponding credit bank and its sub-account. Only the credit in major learning sub-account can participate in grade point calculation and graduation audit. Credit substitution denotes that the credits in the sub-accounts of nonmajor learning, second major learning, learning exchange, changing major and quality development to replace the credits in major learning sub-account for closely integrating professional training and quality education. credit substitution should follow four main principles: firstly the substitutions between the same level or the superior substituting the lower; secondly the overall credit substitutions of learning exchange and changing major; thirdly the credits of quality development substituting that of elective courses; fourthly activity credits substituting practice credits or improving the grade point of relevant courses.

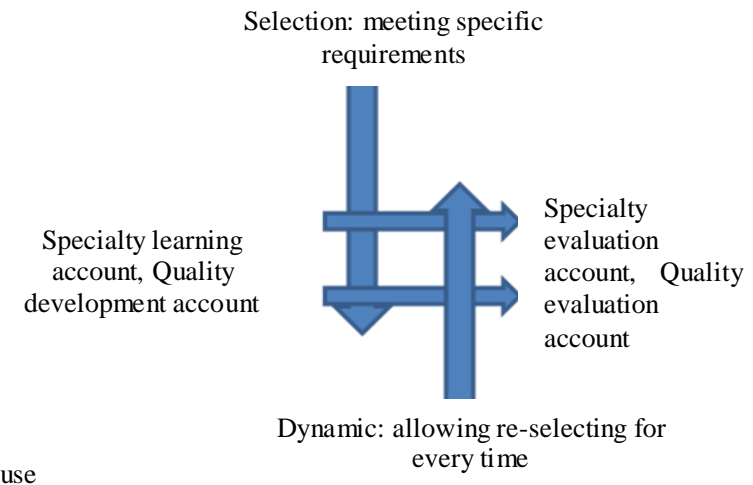

Fig. 5. Credit use every time professional qualification, honors and rewards, practice and paper patent. Set up corresponding sub-account in quality development account to guide students to enhance their comprehensive quality consciously and actively.

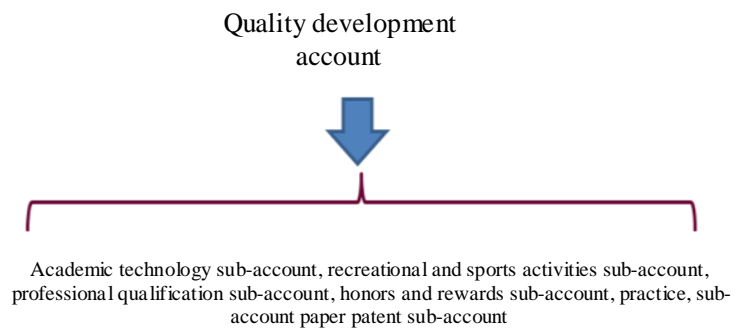

\section{B. Credit Use}

The credits recorded in the credit bank mainly serves as two functions: firstly it is the qualitative proof for students' learning experience and process namely recording the natural status of students' learning includes their courses, participating activities and honors; secondly it is the quantitative evaluation of students' learning performance namely using credits and grade point to quantize students' learning results to appraise, award and graduation audit. Founded on this assumption, two learning evaluation accounts are established to correspond with the major learning account and quality development account. In accordance with the principle of selection and dynamic as well as credits in the corresponding learning account and quality development account, the reports of major learning and quality development are formed as showed in "Fig. 5". The socalled selection means that students can self-select the credits for evaluating when all students' total credits for evaluating (the credits required in the training program) are the same and the credits in account are beyond the required numbers; and when selection applies to quality development reports, students can completely self-choose the credits for evaluating. The socalled dynamic means that students can reselect the credits for evaluating according to self latest learning development and acquirements in different evaluating period. For instance, if a student takes more elective courses of a certain field than being required and gains the corresponding credit, he can use the new credit to substitute the unsatisfying credit for evaluating before. This credit selection mode gives students more choosing space, which to the possible extent, stimulates students' learning subjectivity and inspires their continuous learning improvements.
Specialty learning
report, Quality

development report 


\section{Learning Evaluation}

When implementing credit system, such diversified learning evaluation as process evaluation, final or comprehensive evaluation and special evaluation are selectively done for various demands. Wherein, the process evaluation mainly tests students' learning ability and focuses on learning results and efficiency, which calculates grade points by reducing the actual scores gained by students in course assessment; final evaluation mainly tests students' current learning level and focuses on learning results, which calculates grade points in accordance with the actual scores in course assessment; comprehensive evaluation tests students in accordance with training program's requirements; special evaluation refers to specially inspect the learning status of common curriculum, core courses and module courses, which focuses on students' specialty. Meanwhile, when carrying out learning evaluation, embodying intentionality and highlighting timeliness are particularly emphasized. On one hand, process evaluation can be mainly adopted in the competitive learning evaluation of appraising, awarding and recommending examfree postgraduate; while final evaluation can be mainly used in the non-competitive purpose such as overseas studying and employment. Special evaluation can be done for students' needs. On the other hand, according to learning process, the evaluation is divided into four kinds namely term evaluation, academic-year evaluation, accumulated evaluation and graduation evaluation, and gives evaluation in different phase respectively based on the time node. The interrelations are showed in "Fig. 6". This learning evaluation system simultaneously work in variety of ways and the evaluation results can be selected to apply.
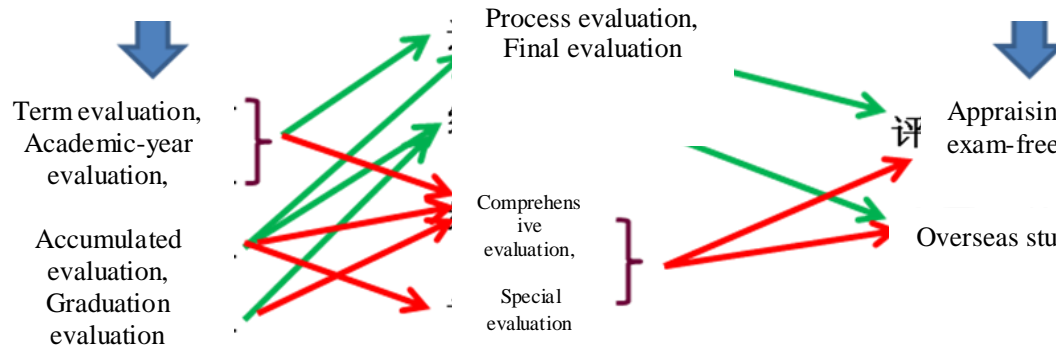

Appraising and awarding, recommending exam-free postgraduate

Overseas study, employment

Fig. 6. Learning evaluation interrelation

\section{CONCLUSION}

Through the analysis of this paper, matched management system is needed to ensure the effective implementation and practice of the new concepts. Under the popularized education background and the process of promoting credit system, to establish and perfect the matched system for the teaching management mode of credit system is a crucial step in promoting the credit system reform in colleges and universities. Whether teaching reform of the credit system can be implemented successfully requires all matched systems in colleges and universities such as a complete personnel management system, financial distribution system, faculty reward system, etc. Being an ever new platform, credit system offers vast space for the sound development and innovative education of higher education, which fosters the establishment of the modern university system. Based on the innovative teaching management, credit system can stimulate students' passion for extensively learning knowledge and participating in quality development activities, which creates a thick cultural atmosphere of initiatively learning, actively progressing and bravely creating. Through practice, it is proved that students' participation and benefits degree extend and deepen than before. Therefore, exploration on the innovation of teaching management mechanism based on credit system is of strategic importance to cultivate high quality talents in the new era.

\section{REFERENCES}

[1] Yan Weilong, Wu Mingzhong. Theoretical Basis and Institutional Guarantee for credit System Reform in Colleges and Universities[J] Educational Research, 2015(7):57-63.

[2] Tong Chi. Application Research on Credit System Reform of Medical Adult Higher Education[J]. China Adult Education, 2015(9)

[3] Xia Liyan. Student-oriented American Higher Education System[J]. Journal of Educational Science of Hunan Normal University, 2011, 10(1):78-81.

[4] Guo Yanchun. The Exploration and Practice of Implementing GPAcredit System Management[J]. Heilongiiang Education(Higher Education Research \& Appraisal), 2011 (1) : 45-46.

[5] Hu Xiongbin. The Difference and Enlightenment of the Credit System in Colleges and Universities[J]. Journal of Wuhan University of Technology(Social Science Edition), 2011，24(1); 136-140.

[6] Guo Weiwei, Changqing, Du Ruoyu. Research on the Problems and Countermeasures of College Credit System in Practical Teaching[J]. Journal of Higher Education, 2015(19):177-178.

[7] Liu Min, Xu Jing, Li Meifang. Problems and Countermeasures of the Construction of Credit System in Colleges and Universities in China--Take Yantai Area as an Example[J]. Education Forum, 2015(19):213214.

[8] Liang Huaiyu, Xue Lihua, Zhang Zhijun. Problems and Countermeasures in Achievement Management of Colleges and Universities under the Credit System---Take Inner Mongolia University for Nationalities as an Example[J]. Higher Education Forum, 2015(11). 